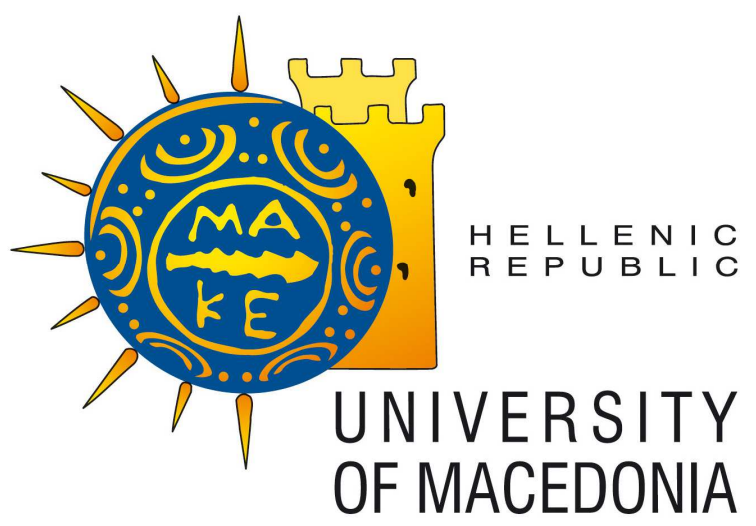

ISSN 1791-3144

\author{
University of Macedonia \\ Department of Economics
}

Discussion Paper Series

\title{
Dynamic Analysis of the Income-Pollution Relationship in a Two-country Setting
}

\author{
Eleftherios Filippiadis and Anastasia Litina
}

\section{Discussion Paper No. 1/2021}




\title{
A Dynamic Analysis of the Income-Pollution Relationship in
}

\section{a Two-country Setting}

\author{
Eleftherios Filippiadis;, Anastasia Litina ${ }^{\dagger}$
}

\begin{abstract}
This research explores the presence of the income-pollution relationship in a dynamic twocountry setting. We argue that the initial conditions of an economy, as described by its initial stock of physical capital, its total factor productivity, and the degree of environmental awareness, are critical determinants of the income-pollution paths. More importantly, these initial conditions have a more pronounced effect in a world where economies interact with one another and transboundary and global pollutants are affecting more than one country. We show that, in the presence of pollution externalities between two countries, the income-pollution paths these countries follow depend on the stage of development of each country, on their relative and absolute productivities, on the degree of environmental awareness and on the transboundary nature of the pollutants. In a two-country setting with pollution externalities even more complex patterns may arise compared to single country models, thereby confirming the nonlinear effect of growth on environmental outcomes. It is shown that even small asymmetries span income-pollution relationships that are significantly different than the prescribed inverted U-shaped patterns.
\end{abstract}

Keywords: Environmental Kuznets Curve, Environmental poverty trap, TFP asymmetry, Transboundary pollutants

JEL classification: O13, Q01, Q56

\footnotetext{
*Department of Economics, University of Macedonia. Corresponding author: efilipp@uom.edu.gr

$\dagger$ Department of Economics, University of Macedonia
} 


\section{Introduction}

Income growth and environmental quality are two particularly important determinants of social welfare that are linked through the Environmental Kuznets Curve hypothesis (EKC). The Environmental Kuznets Curve postulates that at the early stages of economic development the environment deteriorates. However, there is a critical income level beyond which income growth is associated with improvements in environmental quality. Graphically, this can be represented by an inverted-U shaped curve. But does the EKC exist? This hypothesis has been supported by numerous studies and rejected by many others. The prolonged controversy over the EKC is not surprising since its acceptance or not has very important policy implications. The environment can benefit from growth stimulating policies only when the income-pollution relationship turns negative beyond a reasonable level of income. Otherwise, social welfare may decrease in the long run due to catastrophic effects

of growth on the natural ambient. However, the relationship between income and pollution is far more complex than responding to the above question with a simple yes or no.

The literature on EKC starts in the early 90's with the seminal paper of Grossman and Krueger (1993) and the World Development Report of Shafik and Bandyopadhyay for the World Bank (1992) showing that the EKC describes the evolution of some pollutants. Many theoretical models, both static and dynamic, have been developed subsequent to these studies, and different explanations have been offered. The most prominent explanations theoretical research has offered are high income elasticity for environmental quality (Selden and Song (1994)), increasing returns to abatement (Andreoni and Levinson (2001)), and pollution havens due to international trade (Copeland and Taylor (1995)).

The majority of the models proposed in the literature are single agent models. This naturally raises the question: How well do these models picture the income-pollution relationship when the international externalities of transboundary and global pollutants are disregarded? When deciding production technology countries indirectly choose their emissions level. Hence, even in the absence of trade, countries interact since transboundary emissions of one hurt the others and vice versa. Therefore, emissions are strategic complements and countries act strategically engaging in a pollution 
game. Will a country's strategic behaviour affect the shape of the EKC?

The present paper investigates the income-pollution relationship for transboundary pollutants. We modify the proposed model by Diamantoudi and Filippiadis (2012) to allow for endogenous structure in the evolution of output. More specifically, we use an overlapping generations (OLG) model where households live for two periods. In the first period of their life households decide over the pollution technology to be used in the production and their savings for the next period. They receive disutility from current pollution. Output is produced according to a modified $A K$ process. This model allows for the analysis of transboundary pollutants and incorporates differences in total factor productivity (TFP), initial endowments of capital, and environmental awareness. The effects of these differences on the income-pollution relationship are analyzed. The present model predicts an $\mathrm{EKC}$ in the case of a single country only when the steady state value of capital is relatively high, a result that is in line with the intuition behind the EKC hypothesis. The effect of changes in productivity and/or in environmental awareness on the steady state values of capital and emissions are also analyzed. In the case of two identical countries it is shown that the existence and uniqueness result in Diamantoudi and Filippiadis (2012) can be preserved.

\subsection{Literature Review}

Transboundary and global pollutants are subject to empirical analysis in the more recent EKC literature. Local pollutants like $\mathrm{SO}_{2}, \mathrm{NO}_{x}$, and heavy metals tend to have immediate effects on the environment and, consequently, on public health. As a result, these pollutants are more likely to exhibit the inverse-U pattern in the income-pollution relationship. Transboundary pollutants, on the other hand, such as $\mathrm{CO}_{2}$ and other greenhouse gases, do not seem to follow the path expected by the EKC theory. Instead of an inverted U-shaped curve, global pollutants often exhibit a strictly monotonic relationship between per capita income and emissions with the two being positively related. The reason is that transboundary pollutants do not seem to have an immediate and easily recognized effect on people's well-being. Moreover, these emissions are tied to energy consumption, when current technology cannot support the exponentially increasing demand for energy with solely 
environmentally friendly production processes. As a result, even if transboundary pollutants exhibit the EKC property, the turning point is expected at higher per capita income compared to the case of local pollutants. Due to the reasons presented above, emissions of transboundary pollutants remained unregulated for longer compared to local pollutants. Even when scientists presented their findings about the damage that global pollutants can cause (e.g., ozone layer depletion, global warming), regulating these emissions required action to be taken at an international level. International environmental agreements are slow processes, they usually fail to involve all the major polluters, and their targets are often missed by far (e.g., the Kyoto Protocol).

Many of these problems have been mitigated in recent years. Scientific research on the results of global pollution and education has improved public awareness (Balaguer and Cantavella, 2018; Chen et al., 2019). International negotiations have resulted in "[o]ver 1,000 international environmental agreements ... since the United Nations Conference on the Human Environment (Stockholm Conference) in 1972," (Marrouch and Chaudhuri, 2016). Innovative green production processes, induced by regulatory pressure, are becoming cost-efficient leading to an increasing number of firms adopting them (Peuckert, 2014).

In the recent literature about the $\mathrm{CO}_{2}$ emissions, the existence of an EKC path cannot be confirmed or rejected with certainty. Galeotti et al. (2006) estimated an EKC with a reasonable turning point for the developed countries (OECD members) but not for the developing countries. The robustness of their findings was checked with the use of different data sets, and with the use of different functional forms of the regressions. However, more recently Beck and Joshi (2015), using data on $\mathrm{CO}_{2}$ emissions, confirm the EKC pattern for non-OECD countries while showing that the pattern of the income-pollution relationship for the OECD countries is N-shape. Yaguchi et al. (2007) used data from China and Japan to investigate the dynamics of $\mathrm{SO}_{2}$ and $\mathrm{CO}_{2}$ with the $\mathrm{EKC}$ hypothesis to be clearly rejected for the case of $\mathrm{CO}_{2}$ emissions. On the other hand, Apergis and Ozturk (2015) used data from 14 Asian countries to confirm the EKC pattern. Wagner and MullerFurstenberger (2007) question the results of the empirical research on $\mathrm{CO}_{2}$ emissions claiming that the econometric techniques used are often inappropriate. 
The review of the EKC's literature shows that the theoretical models proposed are inadequate to describe the cases of transboundary and/or global pollutants. It is a common characteristic of these models that are single-country models with two immediate implications: (i) countries that share the same technological and demand parameters should follow the same income-emission path independently of their initial income, and (ii) the pollution externality is restricted within the borders of a single country. Diamantoudi and Filippiadis (2010) and Hutchinson and Kennedy (2014) develop static models to explore the income-pollution relationship for transboundary pollutants assuming exogenous growth. Both papers find that even identical otherwise countries will follow different income-pollution paths depending on their relative position on the world income distribution. Boucekkine et al. (2011) following a dynamic game approach to explore the trade-off between environmental quality and economic performance in a two-country setting shows that cooperation between the countries cannot be reached and each country acts selfishly.

The dynamic analysis of income growth and pollution can be challenging. However, overlapping generations (OLG) models allow the separation of intergenerational aspects from intertemporal choices. OLG models have been often used in the Environmental Kuznets Curve literature. John and Pecchenino (1994) use a general equilibrium OLG model to analyze the income pollution relationship. Their model predicts the existence of EKC while under certain conditions it gives rise to Paretoranked multiple equilibria. Their model has been challenged by Prieur (2007) who extends their model by introducing irreversibility of the stock pollution. Wang et al. (2015) also uses an OLG model with population growth to explore the income-pollution relationship and it derives an EKC. It is shown that the emergence of the EKC can be questioned. Unlike John and Pecchenino (1994) our model is not a version of decentralized general equilibrium, but we are analyzing it from the perspectives of a social planner for each country. Since our model does not incorporate stock feedback effects of pollution our analysis is irrelevant to Prieur (2007). Finally, unlike Wang et al. (2015) our model does not consider population growth.

Another difference of our model compared to the aforementioned studies is that we assume that the damage function only affects the young generation. Drawing inferences from two different strands 
of the literature, we argue that this is a plausible assumption. We first rely on the health deficiency accumulation literature. Dalgaard and Strulik (2014) argue that "it may be the optimal strategy to prioritize early-in-life health spending, and thus allow health spending to decline over time." Furthermore, Strulik (2018) argues that "the greatest increase in unhealthy consumption should be observed among the elderly" thus highlighting the fact that the elderly pay less attention to accumulating health capital. To transfer the rationale behind this context into our analytical framework our assumption suggests that young individuals are more likely to consider the implications of pollution as disutility being at an early stage in their life, while older individuals may not view pollution as disutility as it has a minimal effect on the health stock accumulation process or their productivity.

The second strand of literature is coming from the environmental economics literature. Johnson and Schwadel (2018) use the General Social Survey (GSS) for the US during the period 1973-2016 to establish that individuals, when younger, they are more likely to be pro-environment. They thus illustrate that this correlation does not suggest a cohort effect, but instead it is related to aging in the life-cycle process. A similar argument had been made in Kanagy et al. (1994). This empirical finding is then translated in our model into the simplifying assumption that pollution only affects young individuals for the sake of analytical convenience.

We view our paper as important for two reasons. First, because we uncover a multitude of potential patterns once two countries are considered to interact dynamically in terms of pollution. Our model was motivated by the absence of such dynamic interactions in the associated literature. First, there were very few models to study the interplay of more than one countries and the resulting EKC (see e.g., Diamantoudi and Filippiadis, 2012). Second, there was no study to explore this dynamically. We viewed this point as essential because it captures several possibilities in the incomepollution relationship, possibilities that are not solely related to how one country alone behaves but also from the economic behavior and the stage of development of other countries as well.

Second, because this finding highlights the need for international policy to consider this dynamic interplay. While there is already a debate about the scope for international agreements to mitigate the adverse effect of transboundary pollutants, we also show that there is a scope for international 
cooperation for the additional reason that this cooperation may speed up the presence of the turning point in the EKC, an outcome mostly desirable. Or to generalize our finding, we highlight the fact that these international agreements should consider the possibility the policy followed in one country may impose some sort of positive or negative externality into the other country, in term of the speed of achieving (if it does) its EKC, an externality that should be corrected in the context of an agreement.

The remaining of this paper is organized as follows: Section 2 provides the basic setup of the model. Section 3 analyzes the case of a single country. In Section 4 we discuss theoretically the case of two countries. Section 5 conducts a numerical analysis. Section 6 concludes.

\section{The model}

We consider a two-country overlapping generations model where the production process is described by a modified version of the $A K$ growth model. Specifically, we define the potential output, $y_{i, t}^{\prime}$, as country $i$ 's output $(i=1,2)$ associated with the highest level of emissions, i.e.,

$$
y_{i, t}^{\prime}=A_{i}^{\prime} k_{i, t}
$$

where $A_{i}^{\prime}>0$ denotes the total factor productivity and $k_{i, t}$ is the available capital per worker of country $i$ at time $t^{1}$. The actual output is then defined as

$$
y_{i, t}=y_{i, t}^{\prime} \sigma_{i, t}=A_{i}^{\prime} k_{i, t} \sigma_{i, t}
$$

where $\sigma_{i, t} \in(0,1]$ is a pollution technology index. The underlying assumption about this index is that economies can attain a maximum level of output when (i) no resources are devoted to abatement, and/or (ii) the dirtiest production technology is used, hence the emissions level is at its maximum

\footnotetext{
${ }^{1}$ We further assume a constant labour force equal to the country's population and no population growth.
} 
(i.e., $\left.\sigma_{i, t}=1\right)^{2}$. We specify this index as the ratio of actual emissions, $x_{i, t}$, over the maximum emissions, $\bar{x}_{i, t}$, i.e.,

$$
\sigma_{i, t}=\frac{x_{i, t}}{\bar{x}_{i, t}}
$$

Maximum emissions are assumed to be an increasing and concave function of the potential output, that is

$$
\bar{x}_{i, t}=B\left(y_{i, t}^{\prime}\right)^{a}=B\left(A_{i}^{\prime} k_{i, t}\right)^{a}
$$

where $a \in(0,1)$, and $B>0$. The latter is a scale parameter allowing for different emissions per unit of output ratios, while the former is considered as a policy parameter where lower $\alpha$ implies more strict environmental regulation. Note that, by assumption, $\partial \bar{x}_{i, t} / \partial a>0$ and $\partial^{2} \bar{x}_{i, t} / \partial a^{2}<0$ implying that maximum emissions increase with more relaxed environmental policies but even in the absence of such policies there is a finite level of maximum emissions. In our model we have set $a=1 / 2$. Although a strong assumption it is necessary to ensure analytical solutions and tractability of our results. Substituting equations (3) and (4) in (2) and assuming $a=1 / 2$ we get

$$
y_{i, t}=A_{i}^{\prime} k_{i, t} \frac{x_{i, t}}{B\left(A_{i}^{\prime} k_{i, t}\right)^{1 / 2}}=A_{i} k_{t, i}^{1 / 2} x_{i, t}
$$

where $A_{i}=\left(A_{i}^{\prime}\right)^{1 / 2} / B$ denotes the TFP adjusted for pollution. This production function exhibits constant returns to scale to capital and labour and a positive relationship between emissions and production. In particular, when choosing a dirtier technology resulting in more emissions the production increases. This describes a trade-off between production and the adoption of a clean technology. Stokey (1998) also models the correlation between emissions and production as positive. Maximum emissions can be expressed as

$$
\bar{x}_{i, t}=A_{i} B^{2} k_{i, t}^{1 / 2} .
$$

\footnotetext{
${ }^{2}$ Stokey (1998) introduces a similar index of production technology and assumes that "[p]otential output is attained by using all productive resources in the dirtiest way."
} 
Households in these economies live for two periods. For simplicity we normalize the initial populations to unity while assuming no population growth. They receive utility from consumption in both periods of their lives and disutility from pollution while young. This assumption, as explained in the introduction, is supported by empirical findings (see, Johnson and Schwadel 2018, and Kanagy et al. 1994) and relies theoretically on the results of the health deficiency accumulation models (see Strulik 2018, Dalgaard and Strulik, 2014). Pollution in this model can be thought of as local, transboundary, or global. Denoting $x_{t, j}$ the rival country's emissions, generation $t$ 's utility is defined as

$$
U\left(c_{i, t}^{y}, c_{i, t+1}^{o}\right)=u\left(c_{i, t}^{y}\right)+\delta u\left(c_{i, t+1}^{o}\right)-d\left(x_{i, t}+\rho_{i j} x_{j, t}\right)
$$

where $c_{i, t}^{y}$ is their consumption when young, $c_{i, t+1}^{o}$ denotes the consumption when old, $u(\cdot)$ is nondecreasing and concave, $d(\cdot)$ is increasing and convex, $\delta \in[0,1]$ is a parameter of time preference, and $\rho_{i j} \in[0,1]$ is a parameter describing the rate at which a unit of emission from country $j$ affects country $i$, with $\rho_{i j}=\rho_{j i}=0$ describing a local and $\rho_{i j}=\rho_{j i}=1$ describing a global pollutant ${ }^{3}$. To simplify our analysis we set $\delta=1$. During the first period of their life, while young, people must decide the pollution technology to be used. Given the stock of capital at the beginning of the period, the choice of pollution technology determines the actual output according to equation (5). Once generation $t-1$ has claimed their savings, $s_{i, t-1}=c_{i, t}^{o}$, out of the total output produced in period $t$, generation $t$ has to decide how to allocate their disposable output between current consumption and savings. Note that there is no borrowing in this economy, so that $0 \leq s_{i, t} \leq y_{i, t}-s_{i, t-1}$. Assuming full depreciation of capital, the capital's law of motion is

$$
k_{i, t+1}=s_{i, t}
$$

hence

$$
s_{i, t} \in\left[0, y_{i, t}-k_{t}\right]
$$

\footnotetext{
${ }^{3}$ Note that in our model we allow for $\rho_{i j} \neq \rho_{j i}$. For example, in an upstream-downstream pollution model, with country $i$ being upstream and country $j$ being downstream, we can set $\rho_{i j}=0$ and $\rho_{j i}=1$.
} 
Households' per-period budget constraints are

$$
c_{i, t}^{y}=y_{i, t}-s_{i, t}-s_{i, t-1}=y_{i, t}-s_{i, t}-k_{i, t},
$$

and

$$
c_{i, t+1}^{o}=s_{i, t},
$$

for the first and the second period, correspondingly. Finally, emissions $x_{i, t}$ should be non-negative and cannot exceed maximum emission level as this is given by equation (6). Assuming quadratic utility from consumption ${ }^{4}$ and quadratic disutility from pollution, the optimization problem of a social planner who decides consumption between two periods and the level of emissions is given by

$$
\begin{array}{ll}
\max _{x_{i, t} \in\left[0, \bar{x}_{i, t}\right], s_{i, t} \in\left[0, y_{i, t}-k_{i, t}\right]} & U\left(c_{i, t}^{y}, c_{i, t+1}^{o}\right)=c_{i, t}^{y}-\frac{\beta}{2}\left(c_{i, t}^{y}\right)^{2}+\left(c_{i, t+1}^{o}-\frac{\beta}{2}\left(c_{i, t+1}^{o}\right)^{2}\right)-\frac{\gamma_{i}}{2}\left(x_{i, t}+\rho_{i j} x_{j, t}\right)^{2} \\
\text { s.t. } & c_{i, t}=y_{i, t}-s_{i, t}-k_{i, t}, \\
& c_{i, t+1}=s_{i, t}, \\
& y_{i, t}=A_{i} k_{i, t}^{1 / 2} x_{i, t},
\end{array}
$$

where $\beta>0$ is a parameter that is positively related to the degree of relative risk aversion $(R R A)$, and $\gamma_{i}>0$ is an index of environmental awareness. This index of environmental awareness describes how the negative effects of pollution are perceived by each country. Countries that are more environmentally aware better understand the negative consequences of pollution ${ }^{5}$. Equivalently, the optimization problem can be expressed as

$$
\begin{aligned}
\max _{x_{i, t}, s_{i, t}, \lambda_{i, t}, \mu_{i, t}} & L_{i}\left(x_{i, t}, s_{i, t}, \lambda_{i, t}, \mu_{i, t}\right)=\left(A_{i} k_{i, t}^{1 / 2} x_{i, t}-s_{i, t}-k_{i, t}\right)- \\
& -\frac{\beta}{2}\left(A_{i} k_{i, t}^{1 / 2} x_{i, t}-s_{i, t}-k_{i, t}\right)^{2}+\left(s_{i, t}-\frac{\beta}{2} s_{i, t}^{2}\right)-\frac{\gamma_{i}}{2}\left(x_{i, t}+\rho_{i j} x_{j, t}\right)^{2} \\
& +\lambda_{i, t}\left(A_{i} B^{2} k_{i, t}^{1 / 2}-x_{i, t}\right)+\mu_{i, t}\left(A_{i} k_{i, t}^{1 / 2} x_{i, t}-s_{i, t}-k_{i, t}\right)
\end{aligned}
$$

\footnotetext{
${ }^{4}$ Here we consider only the part of the utility that corresponds to $c_{t, 1}$ and $c_{t+1,2}$ such that $u^{\prime}>0$. It can be shown that the optimal values of current and future consumption are such that this condition is not violated.

${ }^{5}$ Chen et al. (2019) have assumed that environmental awareness varies among different countries, suggesting limited public awareness of environmental issues in developing economies. For their empirical analysis they have constructed two indexes of environmental awareness based on regional statistics from Google Trends.
} 
For $i=1,2$, the necessary Kuhn-Tucker conditions are the first order conditions

$$
\begin{aligned}
x_{i, t}: & A_{i} k_{i, t}^{1 / 2}-\gamma_{i}\left(x_{i, t}+\rho_{i j} x_{j, t}\right)-A_{i} \beta k_{i, t}^{1 / 2}\left(A_{i} k_{i, t}^{1 / 2} x_{i, t}-s_{i, t}-k_{i, t}\right)=\lambda_{i, t}-\mu_{i, t} A_{i} k_{i, t}^{1 / 2}, \\
s_{i, t}: & \beta\left(A_{i} k_{i, t}^{1 / 2} x_{i, t}-s_{i, t}-k_{i, t}\right)-\beta s_{i, t}=\mu_{i, t},
\end{aligned}
$$

along with complementarity slackness conditions

$$
\begin{gathered}
\lambda_{i, t}\left(A_{i} B^{2} k_{i, t}^{1 / 2}-x_{i, t}\right)=0, \\
\mu_{i, t}\left(A_{i} k_{i, t}^{1 / 2} x_{i, t}-s_{i, t}-k_{i, t}\right)=0,
\end{gathered}
$$

positivity of the Lagrange multipliers

$$
\begin{aligned}
& \lambda_{t, i} \geq 0, \\
& \mu_{t, i} \geq 0,
\end{aligned}
$$

and feasibility conditions

$$
h_{x}\left(x_{i, t}, s_{i, t}\right)=A_{i} B^{2} k_{i, t}^{1 / 2}-x_{i, t} \geq 0,
$$

and

$$
h_{s}\left(x_{i, t}, s_{i, t}\right)=A_{i} k_{i, t}^{1 / 2} x_{i, t}-s_{i, t}-k_{i, t} \geq 0,
$$

where $h_{i}\left(x_{i, t}, s_{i, t}\right), i=x, s$, denote the respective constraint function. Note that the objective function is defined over the compact set $\left(x_{i, t}, s_{i, t}\right) \subset \mathbb{R}_{+}^{2}$. Moreover, $U_{i}(\cdot)$ is everywhere continuous. Therefore, according to the Weierstrass Theorem, this problem has a global minimum and a global maximum. Furthermore, the constraint qualification is satisfied since the rank of the matrix below equals to the number of the constraints:

$$
\operatorname{rank}\left[\begin{array}{cc}
\frac{\partial h_{x}}{\partial x_{i, t}} & \frac{\partial h_{x}}{\partial s_{i, t}} \\
\frac{\partial h_{s}}{\partial x_{i, t}} & \frac{\partial h_{s}}{\partial s_{i, t}}
\end{array}\right]=\operatorname{rank}\left[\begin{array}{cc}
-1 & 0 \\
A_{i} k_{i, t}^{1 / 2} & -1
\end{array}\right]=2
$$


According to Proposition 6.5 in Sundaram (1996), this ensures that conditions (11)-(18) define the solution $\left(x_{i, t}^{*}, s_{i, t}^{*}\right)$ in the case of a single country, or the best responses $\left(x_{i, t}^{*}\left(x_{j, t}, s_{j, t}\right), s_{i, t}^{*}\left(x_{j, t}, s_{j, t}\right)\right)$ in the case of two countries.

\section{Single country}

In this section we analyze the case of a single country. For simplicity, the country-denoting subscripts are dropped. Given conditions (11)-(18) and setting $\rho_{i j}=0$, the optimal values of emissions and savings are:

$$
x_{t}^{*}= \begin{cases}\frac{\left(2+\beta k_{t}\right) A k_{t}^{1 / 2}}{2 \gamma+\beta A^{2} k_{t}}, & \text { if } k_{t} \geq \Psi \\ A B^{2} k_{t}^{1 / 2}, & \text { otherwise }\end{cases}
$$

and

$$
s_{t}^{*}= \begin{cases}\frac{\left(A^{2}-\gamma\right) k_{t}}{2 \gamma+\beta A^{2} k_{t}}, & \text { if } k_{t} \geq \Psi \\ \frac{1}{2}\left(A^{2} B^{2}-1\right) k_{t}, & \text { otherwise }\end{cases}
$$

where $\Psi=\frac{2\left(\gamma B^{2}-1\right)}{\beta\left(1-B^{2} A^{2}\right)}$ is the boundary condition under the assumption that $1-B^{2} A^{2}<0$. Note that the optimal emissions are always positive. As borrowing is not allowed in our model and savings can never exceed the disposable income in the current period, we require $0 \leq s_{t}^{*} \leq A k_{t}^{1 / 2} x_{t}^{*}-k_{t}$. For the interior solution this condition is expressed by $0 \leq\left(A^{2}-\gamma\right) \leq\left(2 A^{2}-\gamma\right)$ which is true for any $A^{2} \geq \gamma$. For the corner solution this condition is expressed fully by $0 \leq\left(A^{2} B^{2}-1\right) / 2 \leq\left(A^{2} B^{2}-1\right)$ which is true for any $A^{2} B^{2}-1 \geq 0$. In summary, the conditions imposed are $A^{2} \geq \gamma$, and $A \geq \frac{1}{B}$. However, for the remainder of the paper we adopt the stricter condition

$$
A^{2} \geq 18 \gamma, \quad A \geq \frac{1}{B}
$$

so that these properties are preserved for the case of multiple countries as well. 


\subsection{Steady state analysis}

There are two steady state values for capital with one of them being zero. We are interested in the non-zero steady state. Substituting equation (8) in (20) and setting $k_{t+1}=k_{t}=k^{S S}$ one can confirm that the non-zero steady-state value of capital is given by

$$
k^{S S}=\frac{A^{2}-3 \gamma}{\beta A^{2}}
$$

We require that this value is strictly positive. This implies that $A^{2}>3 \gamma$. Note that since the steady-state value of the interior case exists, a country can never experience perpetual growth. The reason is that, even if a country starts at the corner, growing constantly, eventually the boundary condition $k_{t} \geq \Psi$ will bind and it will enter an interior solution where growth comes to an end when the economy reaches its steady state. The non-zero steady state values for emissions and savings are

$$
\begin{gathered}
x^{S S}=\frac{3}{A}\left(\frac{A^{2}-3 \gamma}{\beta}\right)^{1 / 2}, \\
s^{S S}=k^{S S}=\frac{A^{2}-3 \gamma}{\beta A^{2}} .
\end{gathered}
$$

\subsection{Steady-State: Comparative Statics}

We first examine the effects of TFP, environmental awareness and relative risk aversion on the long-run capital. Differentiating (22) with respect to these parameters we get:

$$
\begin{aligned}
& \frac{\partial k^{S S}}{\partial A}=\frac{6}{A^{3} \beta} \gamma>0, \\
& \frac{\partial k^{S S}}{\partial \gamma}=-\frac{3}{A^{2} \beta}<0,
\end{aligned}
$$

and

$$
\frac{\partial k^{S S}}{\partial \beta}=\frac{3 \gamma-A^{2}}{A^{2} \beta^{2}}<0 .
$$


As $s^{S S}=k^{S S}$ the same results hold for savings in the steady state. Note that an increase in TFP will increase the steady state value of capital as expected. It is also interesting to note that increased public environmental awareness will result in a lower steady-state value of capital. When $\gamma$ is increased, it is optimal to reduce emissions in the current period. This will result in lower total output and reduced savings, thus lowering the amount of capital. Finally, an increase in $\beta$ decreases the marginal utility of consumption for any given level of capital. As households have preferences over consumption and clean environment, this implies that emissions will decrease, hence total output and savings will decrease as well.

The effects of the model's parameters on emissions are also analyzed. Differentiating (23) with respect to these parameters we get $\partial x^{S S} / \partial A<0, \partial x^{S S} / \partial \gamma<0$, and $\partial x^{S S} / \partial \beta<0$. As expected, an increase in environmental awareness decreases steady-state emissions. Changes in $\beta$ work similarly. It is worth noticing that under condition (21) the steady-state level of emissions depends monotonically on productivity. This is an immediate result of the model's formulation that allows for emissions to be viewed as a factor of production (see Lopez (1994)) that is substitutable with capital. We see that when the TFP is sufficiently high to guarantee positivity of the solutions, the marginal product of emissions is sufficiently low and the trade-off between capital and emissions in the production process works in favour of capital accumulation. Therefore, the economy ends up with higher capital and lower emissions.

\subsection{Transitional dynamics}

Substituting equation (20) in (8) yields two first-order difference equations that describe the evolution of capital when optimal emissions are interior and corner solution, correspondingly:

$$
k_{t+1}= \begin{cases}\frac{\left(A^{2}-\gamma\right) k_{t}}{2 \gamma+A^{2} \beta k_{t}}, & \text { if } k_{t} \geq \Psi \\ (A-1) k_{t}, & \text { otherwise }\end{cases}
$$


For $k_{t}(0)=k_{0}$ the solutions of these difference equations are:

$$
k^{*}(t)= \begin{cases}\frac{\left(A^{2}-3 \gamma\right) k_{0}}{A^{2} \beta k_{0}+2^{t}\left(\frac{\gamma}{A^{2}-\gamma}\right)^{t}\left(A^{2}\left(1-\beta k_{0}\right)-3 \gamma\right)}, & \text { if } k_{t} \geq \Psi \\ \left(\frac{A^{2} B^{2}-1}{2}\right)^{t} k_{0}, & \text { otherwise }\end{cases}
$$

Non-oscillating convergence to a steady-state value for the interior case implies that $\gamma /\left(A^{2}-\gamma\right)>0$. Perpetual growth for the corner solution is guaranteed under the assumption that $A^{2} B^{2}-1>0$. Both these conditions are met by (21). For the remainder of this paper we require that the parameter values are such that the economy's capital monotonically converges to a positive steady state. We are motivated by the fact that almost all countries are experiencing positive long-run growth. By substituting the solution in the optimal values of emissions and savings we get

$$
x^{*}(t)= \begin{cases}\frac{2+\beta k(t)}{2 \gamma+\beta A^{2} k(t)} A \sqrt{k(t)}, & \text { if } k(t) \geq \Psi \\ A B^{2} \sqrt{k(t)}, & \text { otherwise }\end{cases}
$$

and

$$
s_{t}^{*}= \begin{cases}\frac{\left(A^{2}-\gamma\right) k(t)}{2 \gamma+\beta A^{2} k(t)}, & \text { if } k(t) \geq \Psi \\ \frac{1}{2}\left(A^{2} B^{2}-1\right) k(t), & \text { otherwise }\end{cases}
$$

Despite the analytical form of emission dynamics, it is not possible to derive results about local optima. Thus, the actual shape of emissions through time cannot be derived analytically. However, we can show the following:

Proposition 1 Given a positive growth rate of capital, the evolution of emissions over time can take three possible forms depending on the initial condition, $k_{0}$, and the steady state value of capital, 
$k^{s s}$ :

(i) emissions are monotonically increasing in time, when $k^{s s}$ is relatively low,

(ii) emissions increase but then decrease in time, when $k^{\text {ss }}$ is high and $k_{0}$ relatively low,or

(iii) emissions monotonically decrease in time, when $k^{\text {ss }}$ is high and $k_{0}$ relatively high.

\section{Proof. See Appendix II.}

According to Proposition 1 a country's stage of economic development is crucial for determining the income-pollution relationship. In our steady-state analysis we have found that the steady state value of capital positively depends on the TFP level. Therefore, in agreement with relevant studies showing a positive relationship between the development stage of the economy and the associated TFP (see, Kim and Loayza, 2019), it is logical to expect that developing economies will be facing a lower steady state value of capital than the developed economies. According to Proposition 1, in such economies pollution will monotonically increase with income. On the other hand, developed economies with higher TFPs will be facing higher steady state values of capital. Hence, according to Proposition 1, in developed countries one should expect either a negative relationship between pollution and income or the income-pollution relationship will be described by an inverted U-shape curve. These findings are in agreement with the theoretical work of Chimeli and Braden (2005).

Assuming positive growth rates of capital, the possible trajectories of the emissions over time follow immediately. Emissions will be monotonically increasing in time if $\partial x^{*}[k(t)] / \partial k(t)$ does not turn negative before $k(t)$ reaches its steady state. Otherwise, two cases are possible depending on the level of the initial endowment. Figure 1 shows the two most interesting possible cases ${ }^{6}$. In part (a) of Figure 1 the case of a developing country is shown, where the economy reaches its steady state before the turning point, thus the strictly increasing income-pollution relationship. Part (b) of Figure 1 shows the case of a developed economy, where emissions increase with income but start decreasing before reaching the steady state.

\footnotetext{
${ }^{6}$ The parameter values for deriving these graphs are $k(0)=0.0001, \beta=0.0001, \gamma=0.4$, and $B=10$. TFP in part (a) is set to $A=1.85$ while in part (b) is set to $A=3.4$.
} 


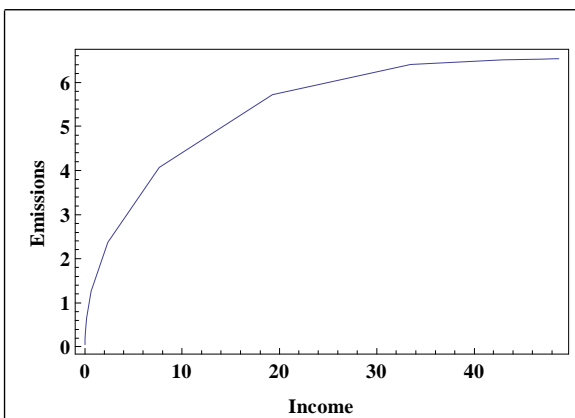

(a)

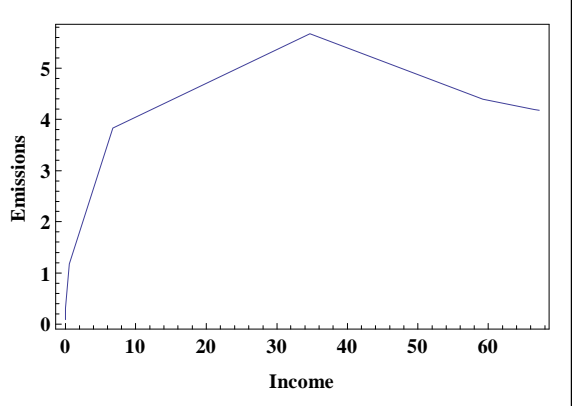

(b)

Figure 1: Emissions over income

\section{Two countries}

When considering two countries, conditions (11)-(18) for $i=1,2$ are used to derive the reaction functions. However, neither existence nor uniqueness of a solution can be guaranteed. We first show that the optimization problem described by (10) can be simplified according to:

Lemma 2 For any positive values of domestic and foreign emissions, country i's optimal savings equals half the disposable income, i.e.,

$$
s_{i, t}^{*}=\frac{1}{2}\left(A_{i} k_{i, t}^{1 / 2} x_{i, t}-k_{i, t}\right) .
$$

Therefore, the following optimization problem is equivalent to problem (10):

$$
\begin{array}{cl}
\max _{x_{i, t}, \lambda_{i, t}} & L_{i}\left(x_{t, i}, \lambda_{i, t}\right)=\left(A_{i} k_{i, t}^{1 / 2} x_{i, t}-k_{i, t}\right)-\frac{\beta}{4}\left(A_{i} k_{i, t}^{1 / 2} x_{i, t}-k_{i, t}\right)^{2} \\
& -\frac{\gamma_{i}}{2}\left(x_{i, t}+\rho_{i j} x_{j, t}\right)^{2}+\lambda_{i, t}\left(A_{i} k_{i, t}^{1 / 2} x_{i, t}-k_{i, t}\right) .
\end{array}
$$

Proof. See Appendix II.

Clearly, the objective function of country $i$ 's maximization problem is described in reduced form as

$$
\bar{U}_{i}\left(x_{t, i}\right)=\left(A_{i} k_{i, t}^{1 / 2} x_{i, t}-k_{i, t}\right)-\frac{\beta}{4}\left(A_{i} k_{i, t}^{1 / 2} x_{i, t}-k_{i, t}\right)^{2}-\frac{\gamma_{i}}{2}\left(x_{i, t}+\rho_{i j} x_{j, t}\right)^{2}
$$


The reduced form of the optimization problem as described in Lemma 2 simplifies our analysis as it leaves emissions, $x_{i, t}$, the only control variable of country $i$. Furthermore, this result is essential in proving that, for the case of global pollutants, i.e., $\rho_{i j}=\rho_{j i}=1$, a unique solution exists provided that the countries are characterized by identical environmental awareness, i.e., $\gamma_{i}=\gamma_{j}=\gamma$.

Maximization of problem (28) requires the following conditions:

$$
\begin{gathered}
A_{i} k_{i, t}^{1 / 2}-\frac{\beta}{2} A_{i} k_{i, t}^{1 / 2}\left(A_{i} k_{i, t}^{1 / 2} x_{i, t}-k_{i, t}\right)-\gamma_{i}\left(x_{i, t}+\rho_{i j} x_{j, t}\right)=\lambda_{i, t}, \\
A_{i} B^{2} k_{i, t}^{1 / 2}-x_{i, t} \geq 0, \\
\lambda_{i, t}\left(A_{i} B^{2} k_{i, t}^{1 / 2}-x_{i, t}\right)=0,
\end{gathered}
$$

and

$$
\lambda_{i, t} \geq 0
$$

Conditions (29)-(32) for $i=1,2$ characterize the solution of the pollution game. The optimal emissions can be shown to be

$$
x_{i, t}^{*}=\left\{\begin{array}{l}
A_{i} B^{2} k_{i, t}^{1 / 2} \\
\frac{A_{i} k_{i, t}^{1 / 2}\left(2+\beta k_{i, t}\right)\left(\beta A_{j}^{2} k_{j, t}+2 \gamma_{j}\right)-2 \rho_{i j} \gamma_{i}\left(2+\beta k_{j, t}\right) A_{j} k_{j, t}^{1 / 2}}{\beta A_{i}^{2} k_{i, t}\left(\beta A_{j}^{2} k_{j, t}+2 \gamma_{j}\right)+2 \gamma_{i}\left(\beta A_{j}^{2} k_{j, t}+2 \gamma_{j}\left(1-\rho_{i j} \rho_{j i}\right)\right)} \\
\frac{A_{i} k_{i, t}^{1 / 2}\left(2+\beta k_{i, t}\right)-2 \rho_{i j} \gamma_{i} B^{2} A_{j} k_{j, t}^{1 / 2}}{\beta A_{i}^{2} k_{i, t}+2 \gamma_{i}}
\end{array}\right.
$$

where the top case represents maximum emissions for country $i$, the middle case corresponds to country $i$ 's emissions when both countries emit less than maximum, and the bottom case represents emissions of country $i$ when the rival country emits at the maximum. A final observation regarding $x_{i, t}^{*}$ is that $(33)$ does not guarantee non-negativity of the emissions. We assume that the parameter values along with the current levels of domestic and foreign capital are such that the optimal emissions are non-negative. For the numerical simulation results provided in the following section, if at 
some point $t$, optimal emissions level $x_{i, t}^{*}$ becomes negative it is set equal to zero and it remains zero thereafter.

Note that according to Lemma 2 the optimal savings can be described as

$$
s_{i, t}^{*}=\frac{1}{2}\left(A_{i} k_{i, t}^{1 / 2} x_{i, t}^{*}-k_{i, t}\right)
$$

where $x_{i, t}^{*}$ is appropriately defined by (33). Therefore, economy $i$ 's capital law of motion is

$$
k_{i, t+1}=s_{i, t}^{*}=\frac{1}{2}\left(A_{i} k_{i, t}^{1 / 2} x_{i, t}^{*}-k_{i, t}\right) .
$$

\subsection{Existence and Uniqueness of Solution}

In the optimization problem (10), emissions is the only control variable. The corresponding KuhnTucker conditions of the two countries describe the pollution game. It is then easy to show that, provided that $\gamma_{i}=\gamma_{j}=\gamma$ and $\rho_{i j}=\rho_{j i}=1$, this game satisfies the conditions of Theorem 4.5 in Monderer and Shapley (1996) for a Potential Game as

(i) individual strategy spaces are compact as intervals of real numbers, i.e., $x_{t, i}=\left[0, \bar{x}_{t, i}\right] \subset \mathbb{R}$,

(ii) the payoff functions are continuously differentiable, and the cross-partial derivatives of any two payoff functions are equal, i.e.

$$
\frac{\partial^{2} \bar{U}_{i}}{\partial x_{i, t} \partial x_{j, t}}=\frac{\partial^{2} \bar{U}_{j}}{\partial x_{i, t} \partial x_{j, t}}=-\gamma
$$

Lemma 3 The following is a potential function of the pollution game

$$
P(\mathbf{x})=\sum_{i=1}^{2}\left[\left(A_{i} k_{i, t}^{1 / 2} x_{i, t}-k_{i, t}\right)-\frac{\beta}{4}\left(A_{i} k_{i, t}^{1 / 2} x_{i, t}-k_{i, t}\right)^{2}\right]-\frac{\gamma}{2}\left(x_{i, t}+x_{j, t}\right)^{2}
$$

Moreover, this potential function is strictly concave.

Proof. See Appendix II. 
Therefore, the pollution game described in the present paper is a Potential Game with a strictly concave potential function, hence it satisfies the conditions described in Proposition 4 of Diamantoudi and Filippiadis (2012) for uniqueness of solution.

\subsection{The symmetric case}

Assuming identical countries with $A_{i}=A_{j}=A, \gamma_{i}=\gamma_{j}=\gamma$, and $\rho_{i j}=\rho_{j i}=\rho$, we can proceed with the analytical solution of the model and explore the income-pollution relationship in comparison to the case of a single country. Hence, in the fully symmetric case optimal emissions are defined as

$$
x_{i, t}^{*}= \begin{cases}\frac{\left(2+\beta k_{i, t}\right) A k_{i, t}^{1 / 2}}{2 \gamma(1+\rho)+\beta A^{2} k_{i, t}} & \text { if } k_{t} \geq \widetilde{\Psi} \\ A B^{2} k_{t}^{i, 1 / 2}, & \text { otherwise }\end{cases}
$$

where $\widetilde{\Psi}=\frac{2\left(\gamma B^{2}-1\right)}{\beta\left(1-B^{2} A^{2}\right)}$ is the boundary condition under the assumption that $1-B^{2} A^{2}<0$. Due to complete symmetry of the two countries either both emit at the maximum or both emit at less than maximum. The top case corresponds to country $i$ 's emissions when both countries emit less than maximum while the bottom case represents maximum emissions for country $i$.

Given (36) it is straightforward to show that the steady state values of capital, savings and emission are

$$
k_{i}^{S S}=s_{i}^{S S}=\frac{A^{2}-3(1+\rho) \gamma}{\beta A^{2}}
$$

and

$$
x_{i}^{S S}=\frac{3}{A}\left(\frac{A^{2}-3(1+\rho) \gamma}{\beta}\right)^{1 / 2}
$$

Note that the findings of the comparative statics for the single country case still hold for the fully symmetrix 2-country case. In addition, we get $\partial k_{i}^{S S} / \partial \rho=\partial s_{i}^{S S} / \partial \rho<0$ and $\partial x_{i}^{S S} / \partial \rho<0$, that is all steady-state values decrease with the rate of pollutant dispersion implying that there is a notable strategic effect when considering transboundary pollutants. Provided the decrease in the steady state values of emissions and capital, the steady state actual income also decreases with $\rho$. However, 
we cannot draw any conclusive result about a country's welfare and the changes in $\rho$.

With respect to the transitional dynamics of capital and emissions we are able to show that

$$
k_{i}^{*}(t)= \begin{cases}\frac{\left(A^{2}-3(1+\rho) \gamma\right) k_{0}}{A^{2} \beta k_{0}+2^{t}\left(\frac{(1+\rho) \gamma}{A^{2}-(1+\rho) \gamma}\right)^{t}\left(A^{2}\left(1-\beta k_{0}\right)-3(1+\rho) \gamma\right)} & \text { if } k_{i}(t) \geq \widetilde{\Psi} \\ \left(\frac{A^{2} B^{2}-1}{2}\right)^{t} k_{0}, & \text { otherwise }\end{cases}
$$

and

$$
x_{i}^{*}(t)= \begin{cases}\frac{2+\beta k_{i}(t)}{2(1+\rho) \gamma+\beta A^{2} k_{i}(t)} A \sqrt{k_{i}(t)}, & \text { if } k_{i}(t) \geq \widetilde{\Psi} \\ A B^{2} \sqrt{k_{i}(t)}, & \text { otherwise }\end{cases}
$$

Note that, as a robustness check, when $\rho=0$ (39) reduces to (25). Non-oscillating convergence to a steady-state value for the interior case implies that $(1+\rho) \gamma /\left(A^{2}-(1+\rho) \gamma\right)>0$. Perpetual growth for the corner solution is guaranteed under the assumption that $A^{2} B^{2}-1>0$. Both these conditions are met by (21). Finally, note that if we substitute $(1+\rho) \gamma$ for $\gamma$ in the proof of Proposition 1 the analysis still holds. Therefore, we state the following:

Remark 4 The results described in Proposition 1 are extended to include the case of two symmetric countries.

Unfortunately, no analytical solutions about the dynamics or the steady state of the model can be derived once asymmetries are introduced in the analysis. However, given (33) and (34), we are able to conduct numerical analysis.

\section{Numerical Analysis}

Our numerical analysis aims at exploring the effect of differences in endowments, environmental awareness, and in TFP on the country specific income-pollution relationship. It is shown that this relationship is far more complex than the income-pollution relationship in a single country model. 
For example, it can be shown that, depending on the degree of the asymmetry between two countries, EKC can be confirmed for one country while the other is getting caught into an environmental poverty trap. Figure 2 below depicts such a case. The blue lines correspond to country 1 and the red lines to country 2. Due to asymmetries with respect to initial endowments country 1 is characterized by positive income growth and eventually decreasing emissions while country 2 fails to sustain growth and is trapped into a situation with low income and high aggregate pollution.
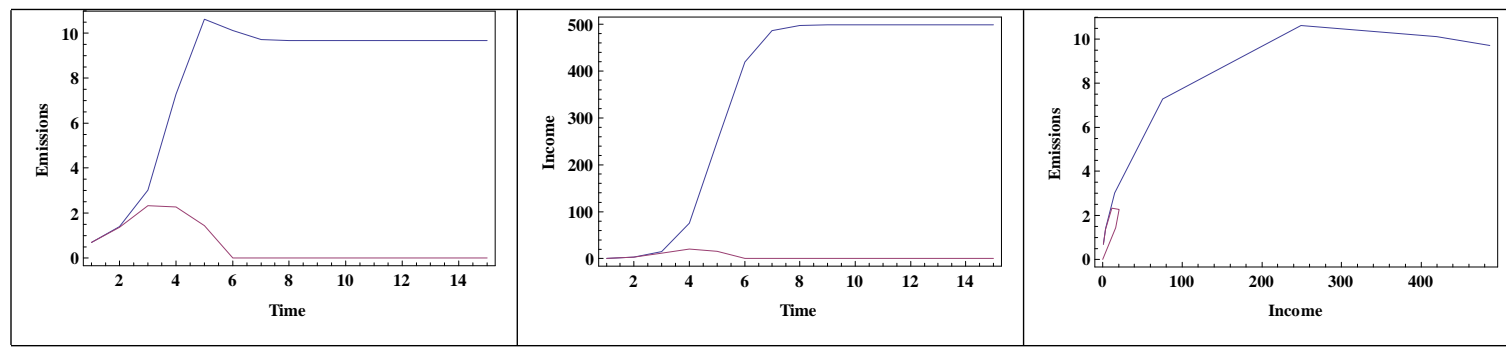

Figure 2: Poverty trap.

For the numerical analysis presented in this section we used Mathematica 9.0. The emissions of a single country can be interior (i.e., $x_{i, t}^{*} \in\left(0, \bar{x}_{i, t}\right)$ ), maximum $\left(i . e ., x_{i, t}^{*}=\bar{x}_{i, t}\right.$ ), or zero (i.e., $\left.x_{i, t}^{*}=0\right)$. Given that there are two countries, this gives rise to $3^{2}=9$ different combinations to be considered when running simulations. However, we can immediately exclude the case where both countries emit zero as this is only possible in the trivial case where both economies start with zero capital. For all the remaining cases the proper boundary conditions have been considered. The parameter values have been chosen so that $(i)$ when starting from the same initial conditions, two symmetric countries will converge to a positive steady state, and (ii) when a country follows the upper boundary path on emissions it is strictly increasing. The former condition implies that $A_{1}=A_{2} \geq 6 \gamma$ when $\gamma<0.25$, or $A_{1}=A_{2} \geq 1+2 \gamma$ otherwise. The latter condition implies that $A_{i}>1 / B$. Table 1 in Appendix I presents the nine possible cases. First, we analyze the case with differences in endowments. Second, we incorporate TFP differences. The analysis with respect to pollution spillover effect and environmental awareness differences follows. 


\subsection{Asymmetric case: differences in initial endowments}

When considering multiple countries the income-pollution relationship has no clear "shape" even if the countries are completely symmetric in everything but their endowments. In this subsection we ask the following questions: (i) Does the relatively rich country have a lower/higher emission trajectory over time? (ii) When EKCs are observed, does the relatively rich country have a higher/lower critical income beyond which its emissions decrease? (iii) Which factors of the model increase the probability that the relatively poor country will experience an environmental poverty trap? (iv) Does equal income distribution benefit the environment? To investigate these questions, we considered three levels of aggregate initial endowments, namely "low", "average", and "high." We have set the sum of initial endowments as a percentage $d<100 \%$ of the steady state-value of capital. The critical assumption made is that with an equal income distribution between the two countries, capital will converge to a positive steady state.

\begin{tabular}{|c||c|c|c|c|c|c|c|c|c||}
\cline { 2 - 10 } \multicolumn{1}{c|}{} & \multicolumn{3}{c|}{$\gamma=100$} & \multicolumn{3}{c|}{$\gamma=110$} & \multicolumn{3}{c|}{$\gamma=150$} \\
\cline { 2 - 10 } \multicolumn{1}{c|}{} & Low & Average & High & Low & Average & High & Low & Average & High \\
\hline$A=100$ & 17.4 & 58.0 & - & 14.0 & 33.0 & - & 0.3 & 3.0 & 27.0 \\
\hline$A=102$ & 18.1 & 77.0 & - & 10.0 & 42.0 & - & 0.6 & 4.0 & 43.0 \\
\hline$A=103.5$ & 22.0 & 100.0 & - & 13.1 & 54.0 & - & 1.0 & 6.0 & 68.0 \\
\hline
\end{tabular}

Table 2: The effects of $A$ and $\gamma$ on the $d_{C}$.

Our simulations were inconclusive on answering (i) and (ii). To study the third question we looked for the critical percentage difference in initial endowments, say $d_{C}=\left(k_{0, i}-k_{0, j}\right) / k_{0, j}$, above which the poor country will be caught into a poverty trap. Table 2 , shows these critical values for three different levels of TFP and three different values of environmental awareness for the cases of low, average, and high aggregate initial endowments. For the results of this table, parameters $B$ and $\beta$ were fixed. We observe the following: 
Remark 5 Large income differences can lead the poor country into an environmental poverty trap. The probability of a poverty trap is decreasing in total initial endowments and in productivity, while it is increasing in environmental awareness.

Comparing parts (a), (b), and (c) of Table 2 confirms this Remark. An explanation of this fact is the presence of increasing returns to scale with respect to capital and emissions. Increasing returns to scale clearly benefit the rich country. However, as TFP and/or the total initial endowments increase, the benefits from the IRS are reduced and the rich country loses its strategic advantage. Robustness checks were conducted for alternative combinations of $A$ and $\gamma$ confirming our findings. Note that sensitivity analysis showed that changes in $\beta$ do not affect the numerical results, while there is a critical value of $B$ below which there is a low probability for the poverty trap to occur. No significant differences in our results were found when we controlled for the growth rates. This indicates that in our model, if endowment levels and their growth rates do not work in the same direction, the former have greater impact on the income-pollution relationship than the latter. Finally, our results cannot confirm that income inequalities might be beneficial for the environment.

\subsection{Asymmetric case: differences in initial endowments and in TFPs}

When allowing for differences in TFPs and in endowments various results are derived. First, TFP asymmetries alone can span completely different income-pollution paths for the two countries: the EKC hypothesis can be confirmed for one while the other exhibits increasing emissions with income. Figure 3, depicts such a case where the country with the TFP advantage exhibits an EKC (blue line). Moreover, as the asymmetry in TFPs increase it is more likely for the less productive country to get caught into an environmental poverty trap. 


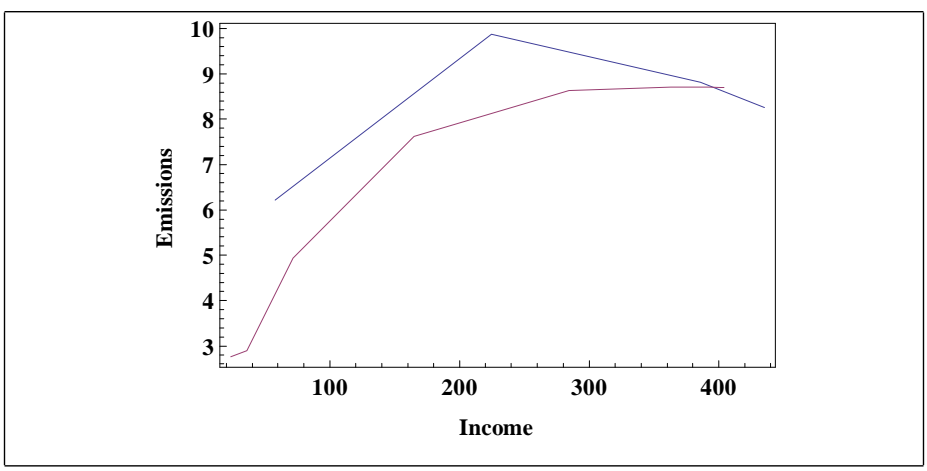

Figure 3: Asymmetries and income-pollution relationship.

Introducing initial endowment along with TFP differences produces far more complex results. For example, if the relatively rich country has an advantage in TFP, the probability of the relatively poor country getting caught into a poverty trap increases. Depending on the initial conditions, it is more likely that the rich country with higher productivity will eventually emit less with income. On the other hand, when the TFP of the rich country is lower, the poor country will eventually become the relatively rich one exhibiting an EKC pattern in the income-pollution relationship. Figure 4 depicts such a case where country 1 with a TFP advantage starts with lower initial capital. Significant productivity advantage of the poor country combined with a small difference in endowments, are the necessary conditions that might create a poverty trap for the initially rich country. Moreover, even if the poor country has higher productivity it might end up in the poverty trap when its initial endowment is not sufficiently large. Finally, it can be shown that in some cases the rich country will have emissions that are increasing in income after the turning point is reached. This is the case of the inverted S-shaped income-pollution curve.
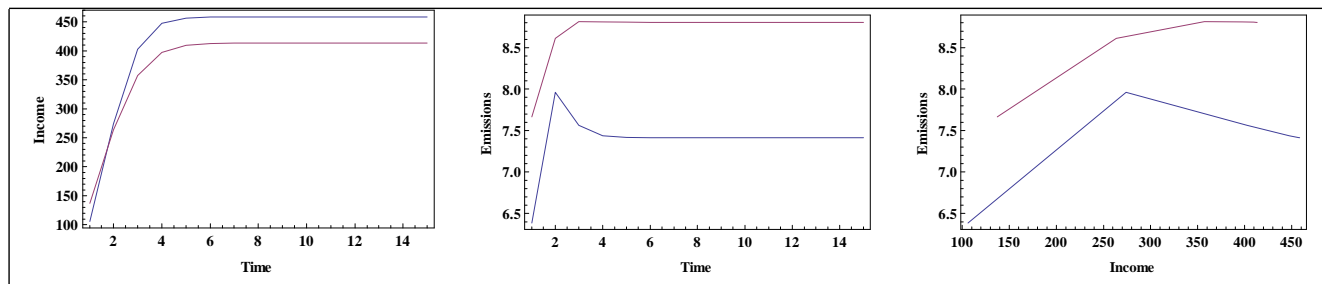

Figure 4: TFP advantage overcoming initial endowment disadvantage. 


\subsection{Asymmetries in environmental awareness and spillover effects of trans- boundary pollutants}

In the final section we provide simulation results when allowing for changes in $\gamma$ and $\rho$. Starting from a completely symmetric situation with strictly local pollutants, i.e., $\rho_{i j}=\rho_{j i}=0$, and an incomepollution relationship described by an EKC, we gradually allow for $\rho$ to increase symmetrically. We then examine (i) whether the EKC is preserved and, (ii) the effects of pollution spillovers on the income-pollution relationship by checking the highest level of emissions reached, $x_{\max }$, and the turning point of income, $y_{T P}$, i.e., the income beyond which the income-pollution relationship turns negative. Table 3 presents simulation results for two different sets of parameter values ${ }^{7}$.

\begin{tabular}{|c|c|c|c|c|c|c|}
\cline { 2 - 7 } \multicolumn{1}{c|}{} & \multicolumn{3}{c|}{ case 1} & \multicolumn{3}{c|}{ case 2} \\
\cline { 2 - 7 } \multicolumn{1}{c|}{} & $x_{\max }$ & $y_{T P}$ & EKC? & $x_{\max }$ & $y_{T P}$ & EKC? \\
\hline$\rho=0.00$ & 0.987 & 0.741 & yes & 5.378 & 85.930 & yes \\
\hline$\rho=0.25$ & 0.975 & 0.596 & yes & 5.043 & 115.614 & yes \\
\hline$\rho=0.50$ & 0.905 & 0.465 & yes & 4.690 & 136.679 & yes \\
\hline$\rho=0.75$ & 0.805 & 0.356 & yes & 4.419 & 148.561 & yes \\
\hline$\rho=1.00$ & 0.720 & 0.824 & yes & 4.215 & 152.523 & no \\
\hline
\end{tabular}

Table 3: The effect of changes in $\rho$.

Starting from a completely symmetric situation with strictly local pollutants and allowing for the spillover effects to change asymmetrically, i.e., country 1's emissions hurt country 2 more than country 2's emissions hurt country1, we observe no regularities in changes in highest emission levels and in turning point incomes. However, as the asymmetry increases, and the situation described resembles more to a pure upstream-downstream pollution model, there is higher probability that country 2 will reach a lower level of highest emissions, a lower turning point income, or get caught

\footnotetext{
${ }^{7}$ The parameter values are $k(0)=0.0001, A_{i}=A_{j}=3.2, \beta=2.15, \gamma_{i}=\gamma_{j}=0.2$, and $B=10$ for case 1 and $k(0)=0.0001, A_{i}=A_{j}=6, \beta=0.01, \gamma_{i}=\gamma_{j}=1.8$, and $B=10$ for case 2 .
} 
into a poverty trap. This is shown in Figure 5, where the income-pollution relationship for country 1 and country 2 are depicted by the blue and the red line, respectively. In part (a) $\rho_{12}=0$ and $\rho_{21}=0.25$, in part (b) $\rho_{12}=0$ and $\rho_{21}=0.50$, and in part (c) $\rho_{12}=0$ and $\rho_{21}=0.66^{8}$.

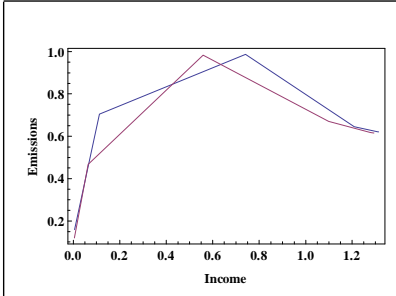

(a)

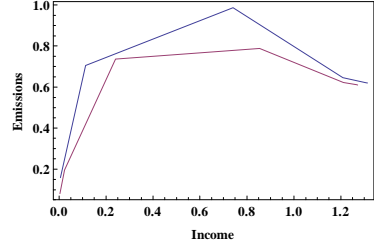

(b)

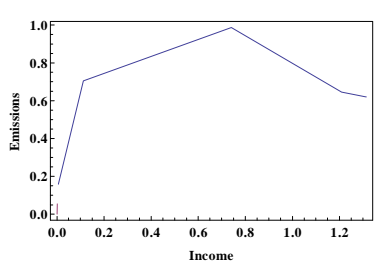

(c)

Figure 5: Asymmetries in pollution spillover.

Finally, we examine the case of asymmetries in environmental awareness. Similarly to the rest of our findings, we observe that as the asymmetry increases, the country with the higher degree of environmental awareness is more likely to have a higher turning point income and a lower level of maximum emissions compared to the rival country, and to get caught into a poverty trap. Table 4 presents some relevant simulation results ${ }^{9}$.

\begin{tabular}{|c||c|c|c|c|c|c|}
\cline { 2 - 7 } \multicolumn{1}{c|}{} & \multicolumn{3}{c|}{ country 1} & \multicolumn{3}{c|}{ country 2} \\
\cline { 2 - 7 } \multicolumn{1}{c||}{} & $x_{\max }$ & $y_{T P}$ & $E K C ?$ & $x_{\max }$ & $y_{T P}$ & EKC? \\
\hline$\gamma_{1}=4.0$ & 1.662 & 86.41 & yes & 1.662 & 86.41 & yes \\
\hline$\gamma_{1}=3.8$ & 1.701 & 17.00 & yes & 1.857 & 79.57 & yes \\
\hline$\gamma_{1}=3.6$ & 2.106 & 23.87 & yes & 2.125 & 66.18 & yes \\
\hline$\gamma_{1}=3.4$ & 2.505 & 32.01 & yes & 1.809 & 22.55 & yes \\
\hline$\gamma_{1}=3.2$ & 2.741 & 39.38 & yes & 0.047 & 0.57 & no \\
\hline
\end{tabular}

Table 4: Asymmetries in $\gamma$.

\footnotetext{
${ }^{8}$ The parameter values for deriving these graphs are $k_{i}(0)=k_{j}(0)=0.0001, A_{i}=A_{j}=3.2, \beta=0.0001$, $\gamma_{i}=\gamma_{j}=0.2$, and $B=100$.

${ }^{9}$ The parameter values for all $i \in\{1,2\}$ are $k_{i}(0)=0.0001, A_{i}=3.2, \beta=2.15, \rho_{i j}=0.5, B=100$. Moreover, it is assumed that $\gamma_{2}=4$.
} 


\section{Conclusions}

The present paper discusses the income-pollution relationship in a multi-country dynamic framework. It follows and completes the work of Diamantoudi and Filippiadis (2012) in that it introduces a dynamic structure in the evolution of capital. This is done by adopting a properly modified overlapping generations model that allows for intergenerational and intertemporal issues to be dis-

connected. In the case of a single country, it is shown that the income-pollution relationship can be either monotonic or it can exhibit the EKC shape. When allowing for two countries, the model described, satisfies the conditions of Diamantoudi and Filippiadis (2012) for existence and uniqueness of the solution for the case of global pollutants and identical environmental awareness. This allows us to analyze numerically the effects of (i) endowment differences, and (ii) productivity differences on the income-pollution relationship. More specifically, our numerical analysis indicates that, even for otherwise symmetric countries, late starters are facing the danger of a poverty trap. This danger is more imminent the lower the TFPs, the lower the global income, and the higher the environmental awareness. For the asymmetric case, our simulations have shown no regularities. However, inverted S-shaped income-emission path can be derived in our model. This analysis confirms the argument that the relationship between income and pollution is more complex than the EKC hypothesis postulates. Finally, we analyze the effects of pollution spillover and of differences in the degree of environmental awareness on the income-pollution relationship. In all cases the EKC hypothesis is more likely to be debunked the greater the underlying asymmetries are.

We view our paper as important for two reasons. First, because we uncover a multitude of potential patterns once two country are considered to interact dynamically in terms of pollution. Our model was motivated by the absence of such dynamic interactions in the associated literature. First, there were very few models to study the interplay of more than one countries and the resulting EKC (see e.g., Diamantoudi and Filippiadis, 2012). Second, there was no study to explore this dynamically. We viewed this point as essential because it captures several possibilities in the emergence of EKC, possibilities that are not solely related to how one country alone behaves but also from the economic behavior and the stage of development of other countries as well. 
Second, because this finding highlights the need for international policy to consider this dynamic interplay. While there is already a debate about the scope for international agreements to mitigate the adverse effect of transboundary pollutants, we also show that there is a scope for international cooperation for the additional reason that this cooperation may speed up the presence of the turning point in the EKC, an outcome mostly desirable. Or to generalize our finding, we highlight the fact that these international agreements should consider the possibility the policy followed in one country may impose some sort of positive or negative externality into the other country, in term of the speed of achieving (if it does) its EKC, an externality that should be corrected in the context of an agreement.

In our analysis we have assumed that for every $i=1,2$ a social planner corresponds to each generation $t$. One can also derive the cooperative solution of the two countries given generation $t$ and compare the two cases. A generalization of the existence and uniqueness result for the asymmetric cases would be examined in the future. A far more daring step will be to convert this model into an infinite horizon model. 


\section{Appendix I:}

\begin{tabular}{|c||c||c|}
\hline \hline Case Code & Emissions of Country 1 & Emissions of Country 2 \\
\hline \hline CS1 & $x_{t, 1}^{*} \in\left(0, \bar{x}_{t, 1}\right)$ & $x_{t, 2}^{*} \in\left(0, \bar{x}_{t, 2}\right)$ \\
\hline CS2 & $x_{t, 1}^{*} \in\left(0, \bar{x}_{t, 1}\right)$ & $x_{t, 2}^{*}=B^{2} A_{2} k_{t, 2}^{1 / 2}$ \\
\hline CS3 & $x_{t, 1}^{*} \in\left(0, \bar{x}_{t, 1}\right)$ & $x_{t, 2}^{*}=0$ \\
\hline CS4 & $x_{t, 1}^{*}=B^{2} A_{1} k_{t, 1}^{1 / 2}$ & $x_{t, 2}^{*} \in\left(0, \bar{x}_{t, 2}\right)$ \\
\hline CS5 & $x_{t, 1}^{*}=0$ & $x_{t, 2}^{*} \in\left(0, \bar{x}_{t, 2}\right)$ \\
\hline CS6 & $x_{t, 1}^{*}=B^{2} A_{1} k_{t, 1}^{1 / 2}$ & $x_{t, 2}^{*}=0$ \\
\hline CS7 & $x_{t, 1}^{*}=0$ & $x_{t, 2}^{*}=B^{2} A_{2} k_{t, 2}^{1 / 2}$ \\
\hline CS8 & $x_{t, 1}^{*}=B^{2} A_{1} k_{t, 1}^{1 / 2}$ & $x_{t, 2}^{*}=B^{2} A_{2} k_{t, 2}^{1 / 2}$ \\
\hline CS9 & $x_{t, 1}^{*}=0$ & $x_{t, 2}^{*}=0$ \\
\hline
\end{tabular}

Table 1: Combinations of emissions intervals 


\section{Appendix II}

Proof of Proposition 1. For the proof of this proposition we have to examine the sign of

$$
\partial x^{*}(t) / \partial t=\partial x^{*}[k(t)] / \partial k(t) \times \partial k(t) / \partial t .
$$

We start with the sign of the $\partial x^{*}[k(t)] / \partial k(t)$. Differentiating equation (26) with respect to the capital yields

$$
\frac{\partial x^{*}[k(t)]}{\partial k(t)}=\frac{A\left(A^{2} \beta^{2} k(t)^{2}-2 A^{2} \beta k(t)+6 \gamma \beta k(t)+4 \gamma\right)}{2 \sqrt{k(t)}\left(\beta k(t) A^{2}+2 \gamma\right)^{2}}
$$

Note that this is a continuous function for all $k(t) \geq 0$. Setting the derivative equal to zero under the assumptions that

$$
\begin{gathered}
\frac{A\left(A^{2} \beta^{2}\left(\frac{A^{2}-3 \gamma}{A^{2} \beta}\right)^{2}-2 A^{2} \beta\left(\frac{A^{2}-3 \gamma}{A^{2} \beta}\right)+6 \gamma \beta\left(\frac{A^{2}-3 \gamma}{A^{2} \beta}\right)+4 \gamma\right)}{2\left(\frac{A^{2}-3 \gamma}{A^{2} \beta}\right)^{1 / 2}\left(\beta\left(\frac{A^{2}-3 \gamma}{A^{2} \beta}\right) A^{2}+2 \gamma\right)^{2}} \\
-\frac{A^{4}-10 A^{2} \gamma+9 \gamma^{2}}{2\left(A^{2}-\gamma\right)^{2} \sqrt{\frac{A^{2}-3 \gamma}{\beta}}} \\
\beta \neq 0 \wedge \frac{1}{A^{2} \beta}\left(-3 \gamma+\sqrt{9 \gamma^{2}-10 A^{2} \gamma+A^{4}}+A^{2}\right) \in \mathbb{C} \backslash\left\{0,-\frac{2}{A^{2} \beta} \gamma\right\} \wedge \\
\wedge A \neq 0 \wedge-\frac{1}{A^{2} \beta}\left(3 \gamma+\sqrt{9 \gamma^{2}-10 A^{2} \gamma+A^{4}}-A^{2}\right) \in \mathbb{C} \backslash\left\{0,-\frac{2}{A^{2} \beta} \gamma\right\},
\end{gathered}
$$

yields two solutions:

$$
\begin{aligned}
& \frac{A\left(A^{2} \beta^{2} k^{2}-2 A^{2} \beta k+6 \gamma \beta+4 \gamma\right)}{2 k^{1 / 2}\left(\beta k A^{2}+2 \gamma\right)^{2}} \\
& \underline{k}(t)= \frac{1}{A^{2} \beta}\left(A^{2}-3 \gamma-\sqrt{9 \gamma^{2}-10 A^{2} \gamma+A^{4}}\right), \\
& \bar{k}(t)=\frac{1}{A^{2} \beta}\left(A^{2}-3 \gamma+\sqrt{9 \gamma^{2}-10 A^{2} \gamma+A^{4}}\right) .
\end{aligned}
$$


It is straightforward to show that

$$
\left.\frac{\partial x^{*}[k(t)]}{\partial k(t)}\right|_{k(t)=0} \rightarrow \infty
$$

and that, under (21),

$$
\left.\frac{\partial x^{*}[k(t)]}{\partial k(t)}\right|_{(1 / 2)(\underline{k}(t)+\bar{k}(t))}=-\frac{\beta^{1 / 2}\left(A^{4}-10 A^{2} \gamma+9 \gamma^{2}\right)}{2\left(A^{2}-\gamma\right)^{2}\left(A^{2}-3\right)^{1 / 2}}<0
$$

Therefore, $\underline{k}(t)$ is a local maximum and $\bar{k}(t)$ is a local minimum of the $x^{*}[k(t)]$. We compare the extrema to the steady state value of capital defined by equation (22). Note that $k^{S S}-\bar{k}(t)=$ $-\left(A^{4}-10 A^{2} \gamma+9 \gamma^{2}\right)^{1 / 2} / \beta A^{2}<0$. This shows that the local minima can never be reached. On the other hand $k^{S S}-\underline{k}(t)=\left(A^{4}-10 A^{2} \gamma+9 \gamma^{2}\right)^{1 / 2} / \beta A^{2}>0$, so that a maximum is always reached. We now turn on the sign of $\partial k(t) / \partial t$ that by assumption is non-negative. There are two cases. When the $k^{S S}$ is reached before $\partial x^{*}[k(t)] / \partial k(t)$ turns negative, the dynamics of emissions over time are positively monotonic. If, on the other hand, $k^{S S}$ is reached once $\partial x^{*}[k(t)] / \partial k(t)<0$ the dynamics of $x^{*}(t)$ will depend only on the initial condition.

Proof of Lemma 2. Consider some $x_{i, t}^{o} \in\left[0, \bar{x}_{i, t}\right], x_{j, t}^{o} \in\left[0, \bar{x}_{j, t}\right]$, and also $s_{i, t}^{*}=\frac{1}{2}\left(A_{i} k_{t, i}^{1 / 2} x_{t, i}-k_{t, i}\right)$. Evaluating $(7)$ at $\left(x_{i, t}^{o}, x_{j, t}^{o}, s_{i, t}^{*}\right)$ yields

$$
\widetilde{U}_{i}\left(x_{i, t}^{o}, x_{i, t}^{o}, s_{i, t}^{*}\right)=\left(A_{i} k_{i, t}^{1 / 2} x_{i, t}^{o}-k_{i, t}\right)-\frac{\beta}{4}\left(A_{i} k_{i, t}^{1 / 2} x_{i, t}^{o}-k_{i, t}\right)^{2}-\gamma_{i}\left(x_{i, t}^{o}+\rho_{i j} x_{j, t}^{o}\right)^{2} .
$$

Consider now any $s_{i, t}^{* *} \neq s_{i, t}^{*}$. Evaluating $(7)$ at $\left(x_{i, t}^{o}, x_{j, t}^{o}, s_{i, t}^{* *}\right)$ yields

$$
\begin{aligned}
\widehat{U}_{i}\left(x_{i, t}^{o}, x_{j, t}^{o}, s_{i, t}^{* *}\right)= & \left(A_{i} k_{i, t}^{1 / 2} x_{i, t}^{o}-k_{i, t}-s_{i, t}^{* *}\right)-\frac{\beta}{2}\left(A_{i} k_{i, t}^{1 / 2} x_{i, t}^{o}-k_{i, t}-s_{i, t}^{* *}\right)^{2} \\
& +\left(s_{i, t}^{* *}-\frac{\beta}{2}\left(s_{i, t}^{* *}\right)^{2}\right)-\gamma_{i}\left(x_{i, t}^{o}+\rho_{i j} x_{j, t}^{o}\right)^{2}
\end{aligned}
$$

Taking the difference

$$
\widetilde{U}_{i}\left(x_{i, t}^{o}, x_{i, t}^{o}, s_{i, t}^{*}\right)-\widehat{U}_{i}\left(x_{i, t}^{o}, x_{j, t}^{o}, s_{i, t}^{* *}\right)=\frac{\beta}{4}\left(k_{i, t}+2 s_{i, t}^{* *}-A_{i} k_{i, t}^{1 / 2} x_{i, t}\right)>0
$$


implying that $s_{i, t}^{*}=\left(A_{i} k_{t, i}^{1 / 2} x_{t, i}-k_{t, i}\right)$ is indeed the maximizer of (10).Therefore, by substituting $s_{i, t}^{*}$ the optimization problem (10) transforms to

$$
\begin{array}{cl}
\max _{x_{i, t}, \lambda_{i, t}} & L_{i}\left(x_{i, t}, \lambda_{i, t}\right)=\left(A_{i} k_{i, t}^{1 / 2} x_{i, t}-k_{i, t}\right)-\frac{\beta}{4}\left(A_{i} k_{i, t}^{1 / 2} x_{i, t}-k_{i, t}\right)^{2} \\
& -\frac{\gamma_{i}}{2}\left(x_{i, t}+\rho_{i j} x_{j, t}\right)^{2}+\lambda_{i, t}\left(A_{i} k_{i, t}^{1 / 2} x_{i, t}-k_{i, t}\right)
\end{array}
$$

Proof of Lemma 3. First, note that $\forall i \in\{1,2\}$, the welfare functions are defined as $U_{i}: X_{i} \rightarrow \mathbb{R}$, where $X_{i} \subset \mathbb{R}$ and they are continuously differentiable. Function $P: X_{i} \rightarrow \mathbb{R}$ is also continuously differentiable and $\forall i \in\{1,2\}$ we have

$$
\frac{\partial P}{\partial x_{i}}=A_{i} k_{i, t}^{1 / 2}\left(1-\frac{\beta}{2}\left(A_{i} k_{i, t}^{1 / 2} x_{i, t}-k_{i, t}\right)\right)-\gamma\left(x_{i, t}+x_{j, t}\right)=\frac{\partial \bar{U}_{i}}{\partial x_{i}}
$$

Therefore, according to Lemma 4.4 in Monderer and Shapley (1996), (35) is a potential function of the pollution game. Moreover, the Hessian of $P(x)$ is given by

$$
H=\left[\begin{array}{cc}
\frac{\partial^{2} P}{\partial x_{1}^{2}} & \frac{\partial^{2} P}{\partial x_{1} \partial x_{2}} \\
\frac{\partial^{2} P}{\partial x_{1} \partial x_{2}} & \frac{\partial^{2} P}{\partial x_{2}^{2}}
\end{array}\right]=\left[\begin{array}{cc}
-\frac{\beta}{2} A_{1} k_{1, t}^{1 / 2}-\gamma & -\gamma \\
-\gamma & -\frac{\beta}{2} A_{2} k_{2, t}^{1 / 2}-\gamma
\end{array}\right]
$$

Consider $\mathbf{z} \in \mathbb{R}^{2} /\left\{\mathbf{0}_{2 \times 1}\right\}$ and construct the quadratic form

$$
\begin{gathered}
\mathbf{z}^{T} H \mathbf{z}= \\
=\left[z_{1} z_{2}\right]^{T}\left[\begin{array}{cc}
-\frac{\beta}{2} A_{1}^{2} k_{1, t}-\gamma & -\gamma \\
-\gamma & -\frac{\beta}{2} A_{2}^{2} k_{1, t}-\gamma
\end{array}\right]\left[\begin{array}{c}
z_{1} \\
z_{2}
\end{array}\right]=-\sum_{i=1}^{2}\left[\left(\frac{\beta}{2} A_{i}^{2} k_{i, t}+\gamma\right) z_{i}^{2}\right]-2 \gamma z_{1} z_{2}<0
\end{gathered}
$$

Thus the Hessian matrix of the potential function is negative definite and, therefore, the potential function $P(\mathbf{x})$ is strictly concave. 


\section{References}

[1] Andreoni, J., Levinson, A., 2001. The simple analytics of the Environmental Kuznets Curve. Journal of Public Economics, 80 (2), 269- 286.

[2] Apergis, N., Ozturk, I., 2015. Testing environmental Kuznets curve hypothesis in Asian countries. Ecological Indicators, 52, 16-22.

[3] Balaguer, J., Cantavella, M., 2018. The role of education in the Environmental Kuznets Curve. Evidence from Australian data. Energy Economics, 70, 289-296.

[4] Beck, K. A., Joshi, P., 2015. An analysis of the environmental Kuznets curve for carbon dioxide emissions: Evidence for OECD and non-OECD countries. European Journal of Sustainable Development, 4(3), 33-45.

[5] Boucekkine, R., Krawczyk, J. B., Vallee, T., 2011. Environmental quality versus economic performance: A dynamic game approach. Optimal Control Applications and Methods, 32(1), $29-46$.

[6] Chen, X., Huang, B., Lin, C. T., 2019. Environmental awareness and environmental Kuznets curve. Economic Modelling, 77, 2-11.

[7] Chimeli, A. B., Braden, J. B., 2005. Total factor productivity and the environmental Kuznets curve. Journal of Environmental Economics and Management, 49(2), 366-380.

[8] Copeland, B.R., Taylor, M.S., 1995. Trade and transboundary pollution. American Economic Review, 85, 716-737.

[9] Dalgaard, C. J., Strulik, H., 2014. Optimal aging and death: understanding the Preston curve. Journal of the European Economic Association, 12(3), 672-701.

[10] Diamantoudi, E., Filippiadis, E., 2012. The Environmental Kuznets Curve in a multicountry setting. Unpublished manuscript. Available at: http://www.cireqmontreal.com/wpcontent/uploads/2012/02/filippiadis.pdf 
[11] Galeoti, M.,Lanza, A., Pauli, F., 2006. Reassessing the Environmental Kuznets Curve for CO2 emissions: A robustness exercise. Ecological Economics, 57, 152- 163.

[12] Grossman, G.M., Krueger, A.B., 1993. Environmental impacts of the North American Free Trade Agreement. In: Garber, P. (Ed.), The U.S. - Mexico Free Trade Agreement. MIT Press, Cambridge, pp. 13-56.

[13] Hutchinson, E., Kennedy, P., 2014. The relationship between emissions and income growth for a transboundary pollutant. Resource and Energy Economics, 38, 221-242.

[14] John, A., Pecchenino, R., 1994. An overlapping generations model of growth and the environment. Economic Journal, 104, 1393-1410.

[15] Johnson, E. W., Schwadel, P., 2019. It is not a cohort thing: interrogating the relationship between age, cohort, and support for the environment. Environment and Behavior, 51(7), 879901.

[16] Kanagy, C. L., Humphrey, C. R., Firebaugh, G.,1994. Surging environmentalism: Changing public opinion or changing publics? Social Science Quarterly, 75, 804-819.

[17] Kim, Y. E., Loayza, N. V., 2019. Productivity growth: Patterns and determinants across the world. The World Bank.

[18] Lopez, R., 1994. The environment as a factor of production: the effects of economic growth and trade liberalization. Journal of Environmental Economics and management, 27, 163-184.

[19] Marrouch, W., Chaudhuri, A. R., 2016. International Environmental Agreements: Doomed to fail or destined to succeed? a review of the literature. International Review of Environmental and Resource Economics, 9(3-4), 245-319.

[20] Monderer, D., Shapley, L., 1996. Potential games, Games and Economic Behaviour, 14, 124-143.

[21] Peuckert, J., 2014. What shapes the impact of environmental regulation on competitiveness? Evidence from Executive Opinion Surveys. Environmental Innovation and Societal Transitions, $10,77-94$. 
[22] Prieur, F., 2009. The Environmental Kuznets Curve in a world of irreversibility. Economic Theory, 40(1), 57-90.

[23] Selden, T., Song, D., 1994. Environmental quality and development: is there a Kuznets Curve for air pollution emissions? Journal of Environmental Economics and Management, 27, 147162.

[24] Stokey, N., 1998. Are there limits to growth? International Economic Review, 39, 1-31.

[25] Strulik, H., 2018. Smoking kills: An economic theory of addiction, health deficit accumulation, and longevity. Journal of Health Economics, 62, 1-12.

[26] Sundaram, R. K., 1996. A first course in optimization theory. Cambridge University Press, New York.

[27] Wagner, M., Müller-Fürstenberger, G., 2008. The Carbon Kuznets Curve: A cloudy picture emitted by bad econometrics? Resource and Energy Economics, 30(3), 388-408.

[28] Wang, S. X., Fu, Y. B., Zhang, Z. G., 2015. Population Growth and the Environmental Kuznets Curve. China Economic Review, 36,146-165.

[29] World Bank, 1992. World Development Report. Oxford Univ. Press, New York.

[30] Yaguchi, Y., Sonobe, T., Otsuka, K., 2007. Beyond the Environmental Kuznets Curve: a comparative study of SO2 and CO2 emissions between Japan and China. Environment and Development Economics, 12, 445-470. 